\title{
Psychosocial interventions for reducing diabetes distress in vulnerable people with type 2 diabetes mellitus: a systematic review and meta-analysis
}

This article was published in the following Dove Press journal: Diabetes, Metabolic Syndrome and Obesity:Targets and Therapy

\author{
Anne Sophie Mathiesen' \\ Ingrid Egerod ${ }^{2}$ \\ Tonny Jensen' \\ Gudrun Kaldan ${ }^{3}$ \\ Henning Langberg ${ }^{4}$ \\ Thordis Thomsen ${ }^{3}$ \\ 'Department of Endocrinology, \\ Abdominal Centre, Copenhagen \\ University Hospital Rigshospitalet, \\ Copenhagen, Denmark; ${ }^{2}$ Intensive \\ Care Unit 4I3I, Copenhagen \\ University Hospital Rigshospitalet, \\ Copenhagen, Denmark; ${ }^{3}$ Abdominal \\ Centre, Copenhagen University \\ Hospital Rigshospitalet, Copenhagen, \\ Denmark; ${ }^{4}$ CopenRehab, Section of \\ Social Medicine, Department of Public \\ Health, Faculty of Health and Medical \\ Sciences, University of Copenhagen, \\ Copenhagen, Denmark
}

\begin{abstract}
Diabetes distress (DD) disproportionately affects vulnerable people with type 2 diabetes mellitus and interventions targeting this population are therefore relevant. A systematic review and meta-analysis was performed to assess the evidence for an effect of psychosocial interventions for reducing DD, and, secondly HbA1c, depression, and health-related quality of life in vulnerable people with type 2 diabetes mellitus. Vulnerability encompasses poor glycemic control (HbA1c $>7.5 \%$ ) and at least one additional risk factor for poor diabetes outcomes such as low educational level, comorbidity, and risky lifestyle behavior. The interventions should be theoretically founded and include cognition- or emotion-focused elements. We systematically searched four databases for articles published between January 1995 and March 2018. Eighteen studies testing a variety of psychosocial interventions in 4,066 patients were included. We adhered to the Cochrane methodology and PRISMA guidelines. Review Manager 5.3 was used for data extraction and risk of bias assessment, and Grades of Recommendation, Assessment, Development and Evaluation for assessing the quality of the evidence. Data were pooled using the fixed or random effects method as appropriate. We investigated effects of individual vs group, intensive vs brief interventions, and interventions with and without motivational interviewing in subgroup analyses. To assess the robustness of effect estimates, sensitivity analyses excluding studies with high risk of bias and attrition $>20 \%$ were conducted. We found low to moderate quality evidence for a significant small effect of psychosocial interventions on DD, and very low to moderate quality evidence for no effect on $\mathrm{HbA1c}$, both outcomes assessed at $3,6,12$, and 24 months follow-up. The effect on depression was small, while there was no effect on health-related quality of life. Exploratory subgroup analyses suggested that interventions using motivational interviewing and individual interventions were associated with incremental effects on DD. Likewise, intensive interventions were associated with significant reductions in both DD and HbA1c.
\end{abstract}

Keywords: diabetes distress, HbA1c, meta-analysis, psychosocial interventions, type 2 diabetes, vulnerable populations

\section{Introduction}

The daily demands of people living with type 2 diabetes mellitus (T2DM) may increase the risk of diabetes distress (DD). ${ }^{1}$ DD is a condition of stressful feelings associated with the challenges of managing diabetes and concerns related to diabetic complications. ${ }^{1}$ The prevalence of DD ranges from $18 \%$ to $35 \%$ in a general population with T2DM, ${ }^{2,3}$ but is substantially higher in ethnic minority subgroups and in hospitalized patients. ${ }^{4} \mathrm{DD}$ is associated with a longer duration of diabetes diagnosis, reduced adherence to treatment ${ }^{5}$ and glycemic control ${ }^{6}$ leading to an
Correspondence: Anne Sophie Mathiesen Department of Endocrinology, Abdominal Centre, Copenhagen University Hospital Rigshospitalet, Blegdamsvej 9, DK-2100

Copenhagen, Denmark

Tel +45 27908669

Fax +4535455213

Email anne.sophie.mathiesen@regionh.dk 
elevated risk of diabetic complications. ${ }^{5,7,8}$ Additionally, DD may progress to depression, ${ }^{9}$ potentially leading to risk of premature death. ${ }^{10} \mathrm{DD}$ is distinct from depression by being far more prevalent ${ }^{11}$ and directly related to diabetes management. ${ }^{11-13}$ It is particularly relevant to address DD given the high prevalence and association with diabetes management in people with T2DM. ${ }^{13}$

DD disproportionately affects vulnerable people with T2DM. ${ }^{2}$ Vulnerable people are those requiring the utmost care and consideration, and who are often characterized by factors associated with an increased risk of $\mathrm{DD},{ }^{14}$ such as low educational level, comorbidity, ${ }^{3}$ and poor glycemic control, which is overrepresented in this population. ${ }^{15}$ Likewise, living alone and risky lifestyle behaviors such as smoking, unhealthy diet, and sedentary lifestyle are more often present in people with T2DM suffering severe and prolonged DD. ${ }^{2}$ The clustering of risk factors for DD can increase hormonal stressors, thereby further affecting blood glucose. ${ }^{16}$ Indeed, trajectories of DD appear most severe and persistent in vulnerable people with T2DM. ${ }^{2}$ Consequently, consideration of DD specifically in vulnerable people with T2DM is relevant for self-management ${ }^{6}$ and prevention of complications in an already susceptible group. ${ }^{5}$

In many clinical settings, interventions for reducing DD are not standard care. ${ }^{11}$ This suggests that caregivers and current health care interventions fail to sufficiently embrace the needs of vulnerable people with T2DM. ${ }^{17}$ The relationship between DD, self-management, and glycemic control has primarily been described associatively. ${ }^{12,18}$ Hence, the causal pathways among these concepts remain unclear. ${ }^{19,20}$ Nevertheless, we hypothesize that interventions specifically targeted toward reducing DD in vulnerable people with T2DM, might potentially improve glycemic control. Due to the complex psychosocial and pathophysiological factors associated with the increased risk of DD among vulnerable people with T2DM, we contend that interventions including a psychosocial approach might better alleviate DD. ${ }^{20}$ Recent reviews of interventions for reducing diabetes-related distress focused on effects in general diabetes populations rather than vulnerable populations. ${ }^{20,21}$ Given the susceptibility of vulnerable people with T2DM to increased levels of DD and diabetic complications, the current review therefore focuses specifically on existing evidence for interventions targeting this subgroup of people. ${ }^{22,23}$

\section{Objective}

To examine the evidence for an effect of psychosocial interventions vs standard care for reducing DD and HbAlc, depression, and health-related quality of life (HRQOL) in vulnerable people with T2DM.

\section{Materials and methods}

This is a systematic review adhering to Cochrane methodology. The review was registered in PROSPERO (The International Prospective Register of Systematic Reviews) with registration number CRD42018064454 and reported according to the PRISMA guidelines. ${ }^{24}$

\section{Types of studies}

We included parallel group randomized clinical trials (RCTs) assessing DD as either a primary or secondary outcome. Exclusion criteria were as follow: cluster-randomized trials due to the potential lack of sensitivity to individual vulnerability characteristics, ${ }^{25}$ cross-over randomized trials, and nonrandomized controlled trials.

\section{Participants}

Participants were vulnerable people with type 2 diabetes duration for more than 1 year, $\geq 18$ years, and $\mathrm{HbA} 1 \mathrm{c}>7.5 \%$ $(58 \mathrm{mmol} / \mathrm{mol})$ at baseline. Vulnerability was defined as in the included studies, but including at least one or more of the following criteria: low socioeconomic status, low health literacy, Hispanic, African-American or other ethnic origin predisposed to an elevated risk of T2DM, ${ }^{26}$ comorbidity, or risky lifestyle defined as body mass index $>30$, sedentary lifestyle, smoking, or alcohol use exceeding 7 units weekly for women and 14 units weekly for men. The vulnerability criteria were informed by recommendations in the PROGRESS $^{27}$ PLUS framework, which is an "equity lens" also applied by the Cochrane Collaboration. The PLUS edition includes individual characteristics such as lifestyle behaviors. We excluded studies including both type 2 and type 1 diabetes as no socioeconomic gradient has been described in type 1 diabetes. ${ }^{28}$

\section{Types of interventions}

Psychosocial interventions that were emotion focused and/ or cognition focused and administered person-to-person, in groups, or digitally, by peers, caregivers or health care professionals, either alone or in combination, for reducing DD in vulnerable people with T2DM. Emotion-focused interventions aim to address patients' self-management practices and thereby influence health outcomes ${ }^{29}$ while cognition-focused interventions involve education and acquisition of diabetesrelated skill training. The theoretical foundations underlying interventions should be prespecified in the methods section 
or study protocol. Included interventions could be brief or intensive and delivered in health care or homecare settings.

\section{Controls}

Usual care as defined in included studies. If studies had more than one arm, the arm most similar to usual care was selected as the control.

\section{Outcomes}

\section{Primary outcome}

DD assessed by Problem Areas in Diabetes (PAID) ${ }^{1}$ or the Diabetes Distress Scale (DDS) at 3, 6, 12, and 24 months. ${ }^{32}$ In DDS, mean item scores of 2.0-2.9 indicate moderate distress, and scores $>3$ indicate clinically important distress requiring intervention. ${ }^{22}$ For the validated 20 -item PAID scale, scores $>40$ indicate clinically important distress. ${ }^{33}$

\section{Secondary outcomes}

HbA1c measured at 3, 6, 12, and 24 months follow-up. For studies where follow-up time points did not match exactly, data from the closest time point were included. Depression was measured with validated instruments such as Patient Health Questionnaire (PHQ-9) ${ }^{34}$ at the longest followup. HRQOL was measured with validated instruments or diabetes-specific instruments such as Diabetes Quality of Life $^{11}$ at the longest follow-up.

\section{Search strategy}

We searched PubMed/Medline, EMBASE, CINAHL, and PsycINFO using different combinations in a search matrix based on the PICO (patient, intervention, comparison, outcomes) format sans comparisons. The latest search was performed on June 19, 2017 supplemented with ongoing alerts from the databases when new studies within the search matrix were published (Table 1). We ended inclusion on March 31, 2018.
We included studies published in English from 1995 and onward. The temporal limitation was chosen to coincide with the development of the PAID instrument in $1995 .{ }^{1}$ Gray literature and reference lists of included studies were screened. Reference lists of reviews and meta-analyses retrieved from the searches were also screened. We screened the search results in Covidence Systematic Review Software. ${ }^{35}$

\section{Identification of relevant studies}

The first and last authors (ASM, TT) independently screened titles and abstracts for eligibility using the following order of importance: RCT, T2DM, DD measured by DDS or PAID, and vulnerable population. Thus, the first "no" was stated as reason for exclusion. We were not masked to authors or journals during the screening process.

\section{Data extraction and management}

Characteristics of the included studies were individually extracted by ASM and GK and included the following: author, title, and year published; Methods: design including number of trial groups, country, and publication date; Participants: number at baseline and follow-up, vulnerability criteria, mean age, mean duration of T2DM, type of treatment (lifestyle, tablets, insulin), comorbidity, and diabetes-related complications. Intervention: setting, intensity, delivery, deliverer involved and training/quality control.

\section{Risk of bias in individual studies}

ASM, GK, and TT independently assessed risk of bias in included studies using the Cochrane Collaboration's Risk of Bias Tool. ${ }^{36}$ Due to the nature of the intervention, blinding of participants and staff was not considered feasible. We considered DD, HRQOL, and depression at high risk of detection bias due to lack of blinding, whereas HbA1was considered at low risk. Disagreements were discussed

Table I Literature search

\begin{tabular}{|l|l|l|}
\hline$\#$ & Keywords & Inclusion \\
\hline I & Patients & $\begin{array}{l}\text { Type 2 diabetes; type 2 diabetes mellitus; diabetes, type 2; T2DM; diabetes T2; diabetes } \\
\text { mellitus; vulnerable population [MeSH]; diabetes mellitus, type 2 [MeSH] }\end{array}$ \\
\hline 2 & Interventions & $\begin{array}{l}\text { Psychological intervention; psychological feedback; psychotherapy; psychological techniques; } \\
\text { digital intervention; internet; cognitive focused intervention; cognitive intervention; cognitive } \\
\text { therapy; cognitive behavior therapy; behavioral intervention; emotional focused intervention; } \\
\text { cognitive behavior therapies [MeSH term]; feedback, psychological }\end{array}$ \\
\hline 3 & $\begin{array}{l}\text { Diabetes distress; distress; diabetes-related distress; problem areas in diabetes; Diabetes } \\
\text { distress scale; PAID; DDS; HbA I c; hb AI c; glycosylated hemoglobin A; medication adherence } \\
\text { [MeSH]; health related quality of life; quality of life [MeSH]; patient compliance [MeSH] }\end{array}$ \\
\hline & Outcomes I AND 2 AND 3. \\
\hline
\end{tabular}


among authors until consensus was reached. We attempted to retrieve protocols in clinicaltrials.gov or published protocols for all included studies to assess potential selective reporting. In studies with missing information, the authors were contacted.

\section{Data analysis}

Meta-analyses were performed using available case analysis and the fixed or random effects method as appropriate. The meta-analyses were pairwise and were weighted by the inverse variance. We assessed the degree of heterogeneity using the $I^{2}$ statistic which measures the percentage of variability in effect estimates due to heterogeneity rather than sampling error. ${ }^{25}$ If $I^{2}>60 \%$, we used the random effects method. We used the Mean Difference (MD) with 95\% CI to assess effects of interventions on continuous outcomes. If different instruments were used, we used the Standardized Mean Difference (SMD). On DD and HbA1c, betweengroups differences at 3, 6, 12, and 24 months follow-up were extracted. On depression and HRQOL, between-groups differences at longest follow-up were used. To increase transparency, risk of bias ratings and meta-analyses were displayed together. We investigated the risk of publication bias using funnel plots, ${ }^{37}$ and data analysis was conducted with Review Manager 5.3.

\section{Subgroup analysis}

The subgroup analyses are moderator analyses that explore effect heterogeneity. Results from subgroup analyses should therefore be interpreted cautiously. ${ }^{25}$ The following exploratory subgroup analyses were planned: 1$)$ effect of brief $(\leq 4$ sessions) vs intensive ( $>4$ sessions) interventions, 2 ) group vs individual interventions, and 3) motivational interviewing vs other interventions, all on DD and $\mathrm{HbA} 1 \mathrm{c}$ at the longest follow-up. The exponential increase in diabetes-related health care expenditures makes it relevant to investigate the effect of less time-consuming interventions ${ }^{38}$ such as brief and group interventions.

Motivational interviewing may potentially be associated with greater reductions in $\mathrm{DD}$ and $\mathrm{HbA} 1 \mathrm{c}$ than interventions not including motivational interviewing in people with both type 1 and type 2 diabetes. ${ }^{21}$ It is relevant to explore whether this is also the case when focusing specifically on vulnerable people with T2DM.

\section{Sensitivity analysis}

We planned to do two sensitivity analyses of the robustness of the effect estimate for the primary outcome DD: 1) excluding studies with high risk of bias (minimum one high risk of bias rating) and 2) excluding studies with high attrition ( $\geq 20 \%)$.

\section{Quality of evidence}

We assessed the overall quality of the evidence for the primary outcome DD and the secondary outcomes HbAlc, depression, and HRQOL using the Grades of Recommendation, Assessment, Development and Evaluation (GRADE). This involved consideration of risk of bias, indirectness, inconsistency, imprecision, and publication bias. The quality of the evidence was rated as high, moderate, low, or very low. ${ }^{39}$ Two authors, ASM and TT, evaluated the quality of the evidence using GRADEpro GDT. Potential disagreements were solved by an arbiter (IE or TJ).

\section{Results}

The search yielded 5,035 potentially relevant studies. Of these, 4,721 were obviously irrelevant, leaving 314 studies that were retrieved for full-text assessment. In total, 18 RCTs involving initial recruitment of 4,066 participants were included. Thirteen studies were protocols for "ongoing studies". Studies were primarily excluded due to not measuring DD, wrong design or intervention (Figure 1).

\section{Characteristics of included studies}

Sample sizes ranged from 47 to $623 .{ }^{40,41}$ Sixteen studies originated from the United States with a concentration of studies from deprived areas in Detroit ${ }^{42,43}$ and Boston. ${ }^{44,45}$ One study was conducted in Germany ${ }^{46}$ and one in India. ${ }^{47}$ Hospital settings were represented in 5 studies and community settings in 13. The studies were published in 2004-2017. Participants were primarily from socioeconomically deprived inner-city areas. Nine studies uniquely included patients from Hispanic, ${ }^{48-51}$ African American, ${ }^{42,43,52,53}$ or Hawaiian or Samoan origin. ${ }^{40}$ In the remaining studies, participants fulfilled our vulnerability criteria primarily due to a high degree of obesity, comorbidity, and/or low educational level (Table 2). At baseline, mean age was $56 \pm 4$ and mean duration of T2DM was $11 \pm 2.5$ years. DD was measured with DDS in two studies ${ }^{50,54}$ and with PAID in 16 studies. Baseline mean DD measured by the 20 -item PAID scale was $39 \pm 10.8$. The five-item short version of PAID was used in three studies. ${ }^{42,47,49}$ Mean $\mathrm{HbA} 1 \mathrm{c}$ at baseline was $8.7 \%(72 \pm 7.7 \mathrm{mmol} / \mathrm{mol})$.

\section{Interventions}

The interventions included combined cognition- and emotion-focused interventions: social support, primarily support groups, some with culturally sensitive elements ${ }^{40,43,48,50}$ in 


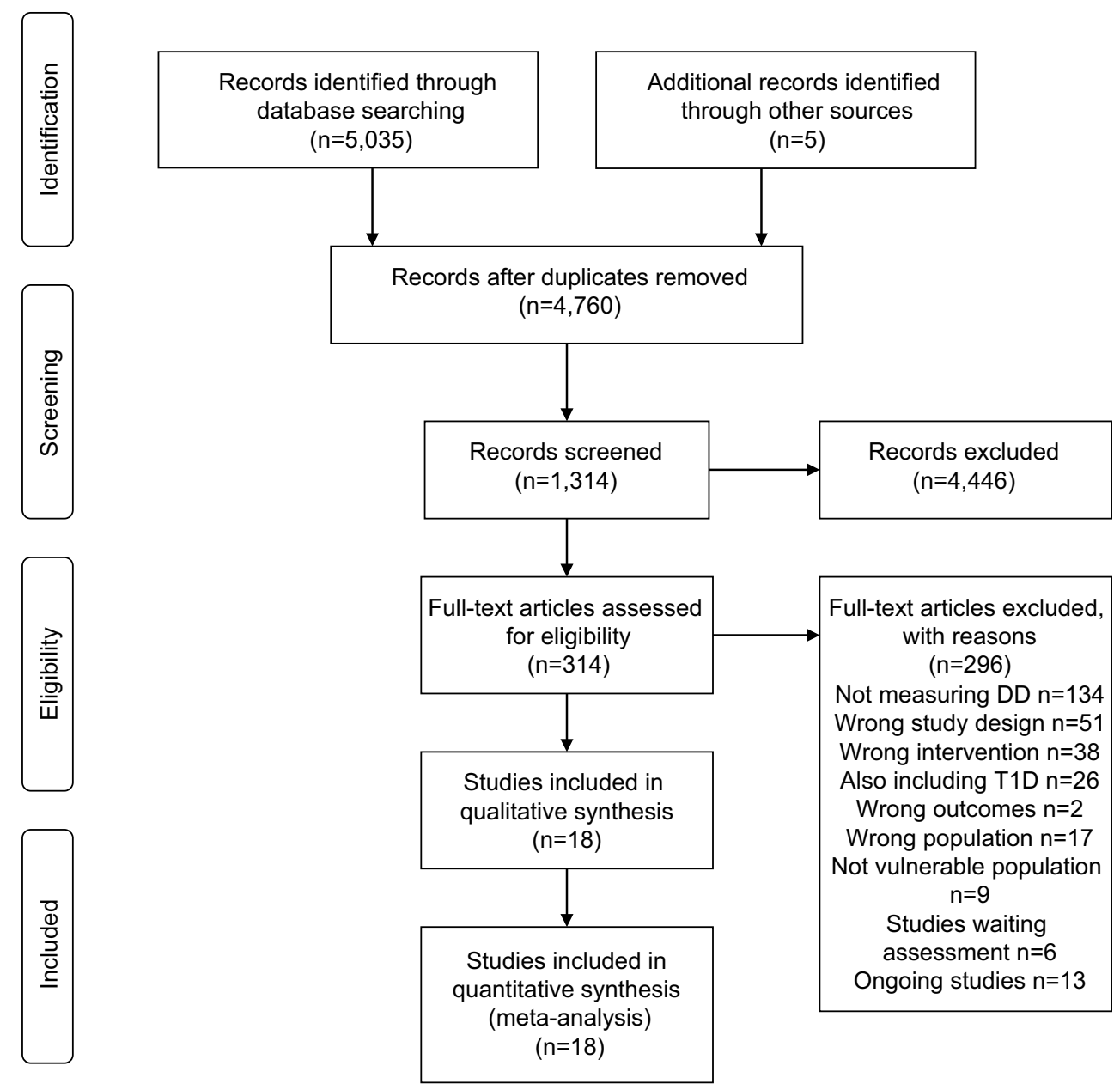

Figure I PRISMA.

Source: From Mohen D, Liberati A, Tetzlaff J, Altman DG, The PRISMA Group (2009). Preferred Reporting Items for Systematic Reviews and Meta-Analyses: The PRISMA Statement. PLoS Med 6(6):e 1000097. doi:10.1371/journal.pubmed 1000097. For more information, visit www.prisma-statement.org.

combination with decision support tools, ${ }^{42}$ conversation maps, ${ }^{41,45}$ coaching, ${ }^{55}$ coping skills training and stress management, ${ }^{49,53}$ empowerment training ${ }^{47,56}$ and social and psychological training. ${ }^{46}$ One study provided a telephone intervention for both the person with T2DM and spouse addressing diabetes-related conflict management with collaborative problem-solving techniques. ${ }^{54}$ Another study involved a family member in supporting the patient using the SMART (Specific, Measurable, Attainable, Relevant and Time-bound) goal approach for behavior change with regard to healthy eating, physical activity, and management of diabetes-related distress. ${ }^{50}$ All interventions included elements of diabetes self-management education of varying intensity. ${ }^{52,57}$

\section{Standard care intervention}

Eleven studies provided enhanced standard care of varying intensity. One study sent a monthly reminder via postcard for 3 months ${ }^{40}$ one sent a monthly report on diabetes goals and status..$^{52}$ Four studies provided two diabetes self-management education sessions lasting 75 minutes by telephone, ${ }^{54}$ one 2 -hour or four 1-hour group sessions. ${ }^{45,49,57}$ One study provided a 90 -minute introduction to a print version of a web decision support tool and two follow-up telephone calls, ${ }^{42}$ one offered free lab tests and consultations, ${ }^{47}$ telephone contact every second week, ${ }^{44}$ another delivered ten diabetes education group sessions ${ }^{53}$ or ten biweekly sessions of 90 minutes duration focusing on acquisition of standardized diabetes knowledge. ${ }^{46}$ Five studies delivered standard treatment, described as general information on diabetes management provided by a health care professional every 3-4 months. Three studies had a wait-list control design, ${ }^{43,50,55}$ and three studies delivered an intervention to all participants prior to randomization. These interventions entailed two telephone calls of 75 minutes 


\begin{tabular}{|c|c|c|c|c|c|c|c|c|c|c|}
\hline 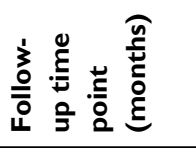 & $\stackrel{ \pm}{\sim}$ & $\begin{array}{l}\simeq \\
0 \\
m\end{array}$ & $\simeq$ & $\stackrel{ \pm}{\sim}$ & $m$ & 0 & 0 & $\begin{array}{l}0 \\
\dot{m}\end{array}$ & $\begin{array}{l}a \\
0\end{array}$ & $\simeq$ \\
\hline 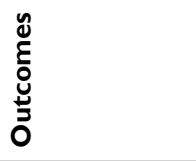 & 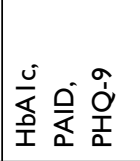 & 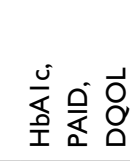 & 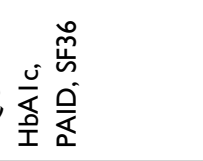 & 宗造崫 & 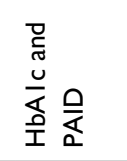 & 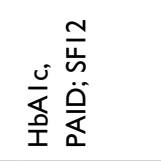 & 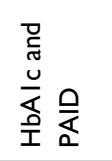 & 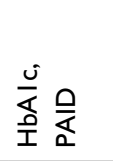 & 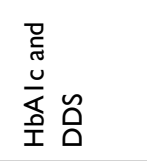 & 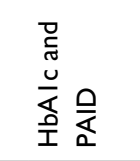 \\
\hline 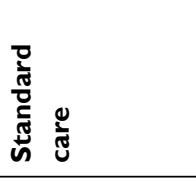 & 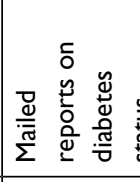 & 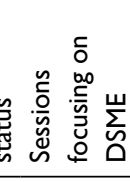 & 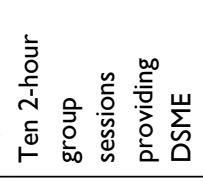 & $\frac{2}{\frac{\pi}{30}}$ & 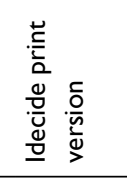 & 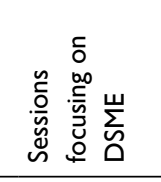 & 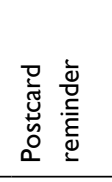 & 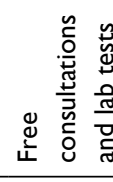 & 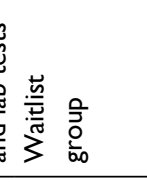 & 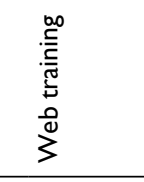 \\
\hline 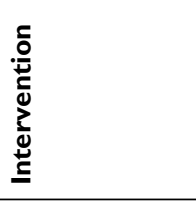 & \multicolumn{3}{|c|}{ 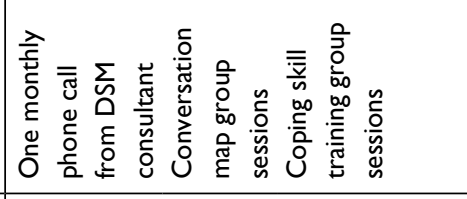 } & 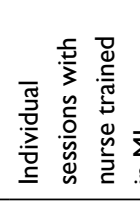 & 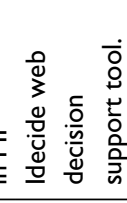 & 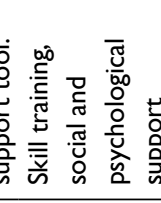 & 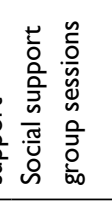 & \multicolumn{3}{|c|}{ 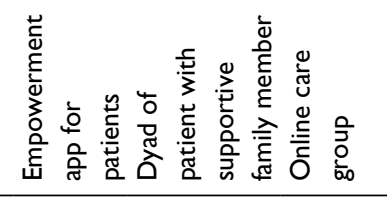 } \\
\hline 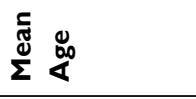 & மீ & เి & $\stackrel{\infty}{+}$ & $\stackrel{\infty}{\circ}$ & 号 & กิ & นn & $\stackrel{\infty}{+}$ & ஸे & 8 \\
\hline 竞 & $\infty$ & $\underline{m}$ & 号 & 号 & $a$ & \pm & $\frac{\alpha}{z}$ & $\frac{\alpha}{z}$ & $\simeq$ & 号 \\
\hline 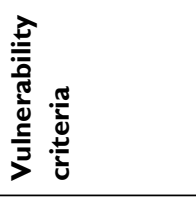 & 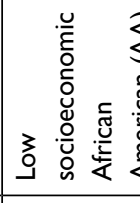 & 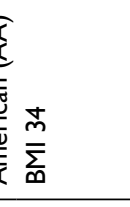 & 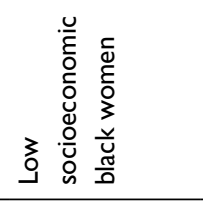 & 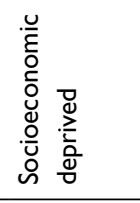 & 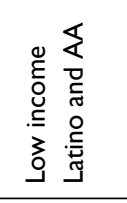 & 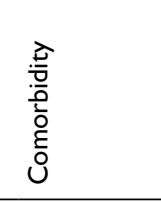 & \multicolumn{3}{|c|}{ 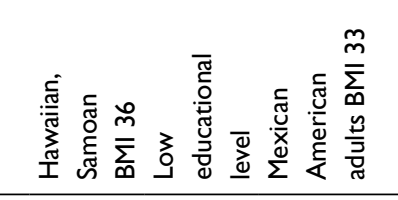 } & 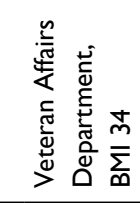 \\
\hline 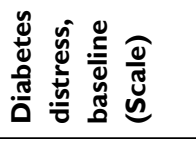 & 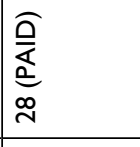 & $\begin{array}{c}\widehat{a} \\
\substack{a \\
Q} \\
\dot{m} \\
\end{array}$ & $\begin{array}{l}\frac{a}{\alpha} \\
\frac{a}{a} \\
\text { n }\end{array}$ & 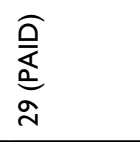 & $\begin{array}{c}\widehat{a} \\
\frac{a}{0} \\
\stackrel{0}{m} \\
\end{array}$ & $\frac{\widehat{a}}{\underline{a}}$ & 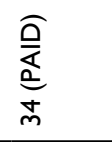 & 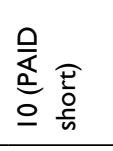 & 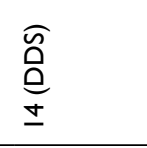 & $\begin{array}{l}\widehat{a} \\
\substack{\alpha \\
\varrho} \\
\stackrel{n}{2}\end{array}$ \\
\hline 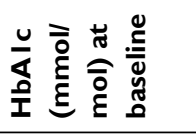 & 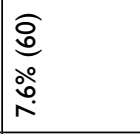 & $\begin{array}{l}\stackrel{0}{o} \\
\stackrel{0}{0} \\
\stackrel{\circ}{+} \\
\infty\end{array}$ & $\begin{array}{l}\text { } \\
\stackrel{0}{0} \\
\text { సें } \\
\infty\end{array}$ & $\begin{array}{l}\frac{\widehat{E}}{\stackrel{0}{\circ}} \\
\stackrel{0}{\circ}\end{array}$ & 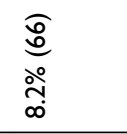 & $\begin{array}{l}\hat{\kappa} \\
\stackrel{0}{\circ} \\
\stackrel{\circ}{\infty} \\
\infty\end{array}$ & 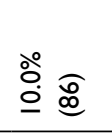 & 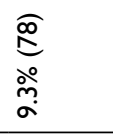 & $\begin{array}{l}\stackrel{0}{\circ} \text { 。 } \\
\text { 요 }\end{array}$ & $\begin{array}{l}\widehat{\bar{\alpha}} \\
\stackrel{\circ}{\circ} \\
\text { o }\end{array}$ \\
\hline 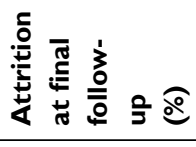 & ก) & 으 & $\stackrel{\infty}{\sim}$ & $\ddot{\sim}$ & 0 & 으 & $\stackrel{ \pm}{\Delta}$ & $\stackrel{\sim}{\sim}$ & - & - \\
\hline 胥 & $\frac{\circ}{m}$ & 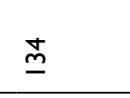 & $\underline{\underline{0}}$ & 占 & $\underline{\infty}$ & $\stackrel{\infty}{\infty}$ & $\hat{f}$ & $\bar{\alpha}$ & 흐 & $\underline{\overline{ }}$ \\
\hline 章焉 & 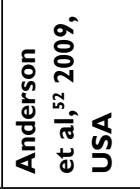 & 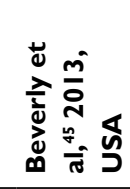 & 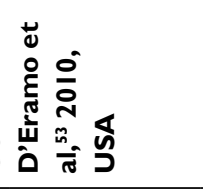 & 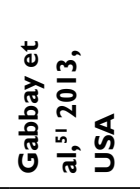 & 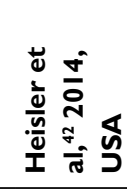 & 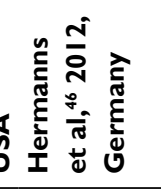 & 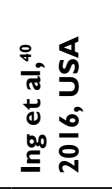 & 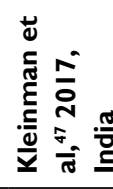 & 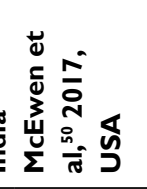 & 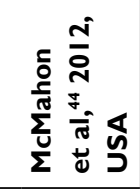 \\
\hline
\end{tabular}




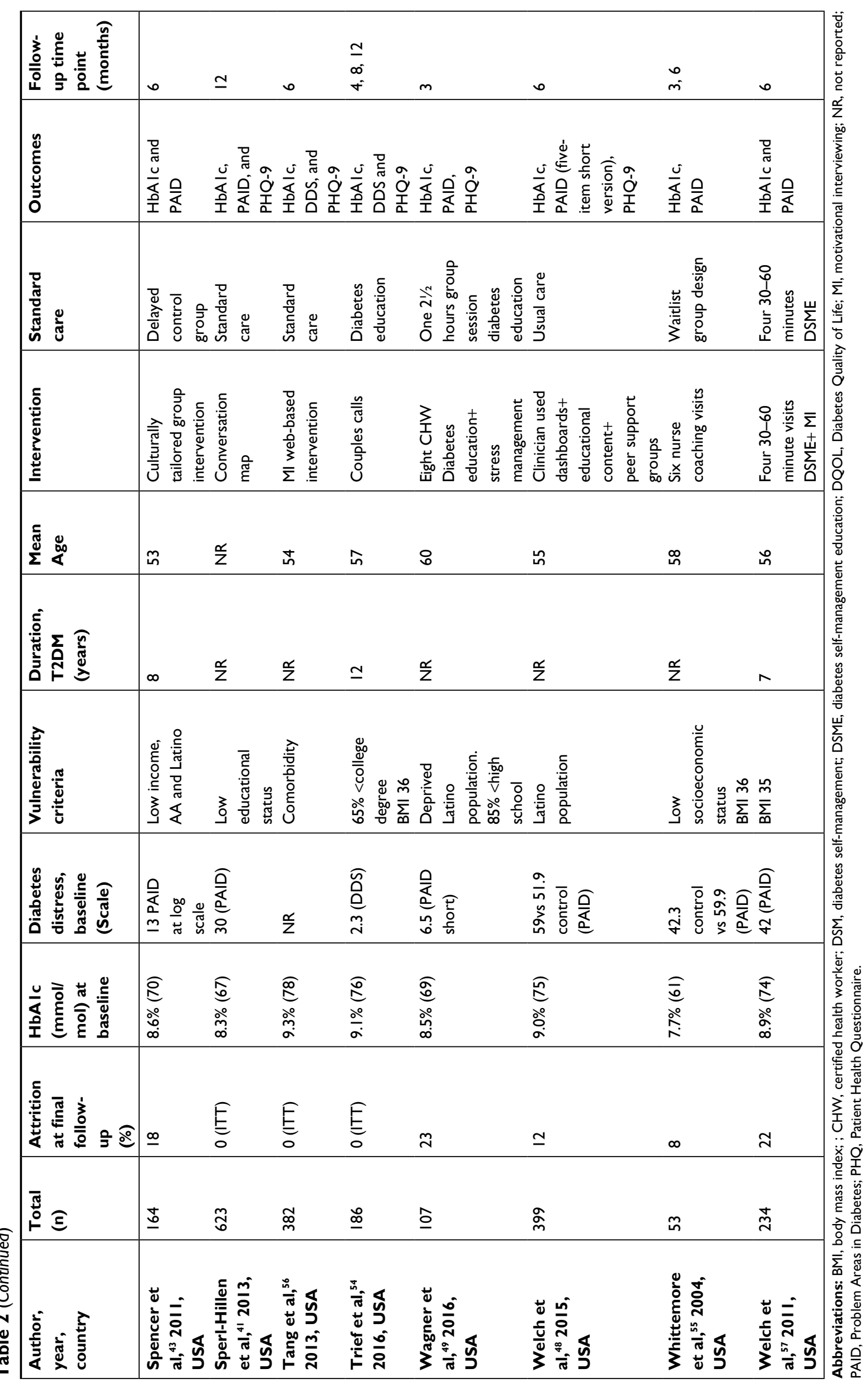


duration, ${ }^{54}$ or 2.5-hour diabetes education group sessions, ${ }^{49}$ or 12 one-hour weekly group meetings. ${ }^{40}$

\section{Deliverers}

The interventions were delivered by community health workers ethnically matched to patients, ${ }^{42,43}$ nurse case managers, ${ }^{51}$ certified diabetes educators ${ }^{40,46}$ in combination with a spouse ${ }^{54}$ or family member, ${ }^{50}$ nurses and dieticians ${ }^{48}$ smartphone applications combined with support from health care providers, ${ }^{47}$ web/telephone, ${ }^{44}$ or telephone.${ }^{54}$ In five studies, the deliverers were trained in motivational interviewing. ${ }^{42,43,51,56,57}$ The training, fidelity, and quality assessment of delivery were most comprehensively described in interventions using motivational interviewing. In these studies, initial training ranged from 2 days ${ }^{57}$ to 80 hours ${ }^{42,51}$ with ongoing supervision of fidelity by use of validated instruments such as the Behavior Change Counseling Index ${ }^{51}$ or the Motivational Interviewing Skills Code. ${ }^{57}$

\section{Risk of bias}

We chose to pool all studies in the meta-analysis and provide a narrative description of risk of bias. We judged this approach to be sound as no studies were judged at high risk of selection bias. Moreover, we performed a sensitivity analysis excluding all studies with at least one high risk of bias rating within the remaining domains in the Cochrane Collaboration's risk of bias tool (performance bias, detection bias, attrition bias, reporting bias, and other bias).

Most studies reported sufficient data on random sequence generation and allocation concealment. Gabbay et $\mathrm{al}^{51}$ moved participants not receiving the intervention to the control group after randomization, resulting in an assessment of high risk of bias. Studies providing comparable enhanced care for control group patients were judged at low risk of performance bias. ${ }^{36}$ Blinding of outcome assessors was explicitly reported in eight studies and insufficiently described in ten. We judged that insufficient blinding affected self-reported outcomes only. Most studies had inconsistencies between protocol and reported results, for example, insufficient information, nonreporting of specific outcomes due to nonsignificant results. Eight authors were contacted for missing information and one responded. ${ }^{47}$ Funnel plots were inconclusive due to less than 10 studies in each assessed outcome. ${ }^{37}$

\section{Diabetes distress}

DD was a secondary outcome in all 18 studies; 16 of these reported complete results on DD. Tang et al. reported on selected subscales of the PAID scale only, ${ }^{56}$ while Welch et al. reported insufficient data. ${ }^{58}$ Two studies had follow-up at 3,6 , and 12 months; ${ }^{45,54}$ two at 3 and 6 months; ${ }^{47,55}$ one at 6 and 12 months, ${ }^{50}$ and the remaining one single follow-up time point. Meta-analysis of seven studies showed a significant reduction in DD at 3 months follow-up; SMD -0.18 (95\% CI $-0.32,-0.03), P=0.02$ (Figure 2 ). The quality of the evidence was low due to indirectness and imprecision (Supplementary material S1). Meta-analysis of eight studies showed a significant reduction in DD at 6 months follow-up; SMD $-0.20(95 \% \mathrm{CI}-0.31,-0.08), P=0.006$. The quality of the evidence was moderate primarily due to a serious risk of bias. Meta-analysis of six studies showed a significant reduction in DD at 12 months follow-up; SMD $-0.21(95 \%$ CI $-0.34,-0.09), P=0.008$. The quality of the evidence was moderate due to a serious risk of bias. Meta-analysis of two studies showed a significant reduction in DD at 24 months follow-up; SMD -0.21 (95\% CI $-0.36,-0.05), P=0.009$. The quality of the evidence was low due to very serious risk of bias.

\section{HbAlc}

HbA1c was the primary outcome in 16 studies and a secondary outcome in two studies. ${ }^{42,50}$ One study had follow-up at 3 , 6 , and 12 months; ${ }^{54}$ two at 3 and 6 months; ${ }^{47,55}$ two at 6 and 12 months, ${ }^{50,56}$ and the remaining studies had one follow-up time point.

Meta-analysis of 18 studies showed no significant effect of interventions on $\mathrm{HbAlc}$ at any time of follow-up: MD $-0.17(95 \% \mathrm{CI}-0.41,0.06), P=0.14$ at 3 months in six studies (low quality evidence; Figure 3 ; Supplementary material S2); MD -0.29 (95\% CI $-0.62,0.05), P=0.09$ at 6 months in nine studies (very low quality evidence); MD 0.02 (95\% CI $-0.17,0.22$ ), $P=0.84$ at 12 months in seven studies (moderate quality evidence); and, $\mathrm{MD}-0.23$ (95\% CI $-0.50,0.04)$, $P=0.10$ at 24 months in two studies (low quality evidence).

\section{Depression}

Depression was a secondary outcome in six studies. Gabbay et al. used the Center for Epidemiologic Studies Depression Scale; ${ }^{51}$ five studies used the PHQ-9 scale. ${ }^{41,49,52,54,56}$ Four studies reported results on depression at $3,{ }^{49} 12,{ }^{54}$ and 24 months. ${ }^{51,52}$ Tang et al merely reported that there was no significant effect on depression. ${ }^{56}$ Sperl-Hillen et al did not provide results that allow mean $+\mathrm{SD}$ to be calculated. ${ }^{41}$ Meta-analysis of four studies showed an SMD $-0.20(95 \%$ $\mathrm{CI}-0.33,-0.07$ ), $P=0.003$ (forest plot not shown) in favor of the intervention at a mean of $16 \pm 10.2$ months of follow-up. 


\begin{tabular}{|c|c|c|c|c|c|c|c|c|c|c|}
\hline \multirow[b]{2}{*}{ Study or subgroup } & \multicolumn{3}{|c|}{ Favours (intervention) } & \multicolumn{3}{|c|}{ Standard care } & \multicolumn{2}{|r|}{ Std. mean difference } & \multirow{2}{*}{$\begin{array}{l}\text { Std. mean difference } \\
\text { IV, Fixed, } 95 \% \mathrm{Cl}\end{array}$} & \multirow{2}{*}{$\begin{array}{l}\text { Risk of bias } \\
\text { A B CDE F G }\end{array}$} \\
\hline & Mean & SD & Total & Mean & SD & Total & Weight & IV, Fixed, $95 \% \mathrm{Cl}$ & & \\
\hline \multicolumn{11}{|c|}{ 2.1.1 Diabetes distress at 3 months follow-up } \\
\hline Beverly 2013 & 27.7 & 16.9 & 59 & 28.9 & 21.1 & 60 & $16.4 \%$ & $-0.06(-0.42,0.30)$ & $\rightarrow-$ & $\odot \odot \odot \odot \odot ? \odot$ \\
\hline Heisler, 2014 (1) & 23 & 28.3 & 87 & 30 & 26.5 & 89 & $24.0 \%$ & $-0.25(-0.55,0.04)$ & -1 & $\odot \odot \odot \odot \odot \odot \odot ~$ \\
\hline Ing 2016 & 29.3 & 20.7 & 22 & 26.2 & 27.5 & 12 & $4.3 \%$ & $0.13(-0.57,0.83)$ & $\longrightarrow$ & $? ?+? \ominus ? \theta$ \\
\hline Kleinman 2017 & 8.7 & 3.5 & 38 & 10.1 & 8.4 & 40 & $10.7 \%$ & $-0.21(-0.66,0.23)$ & & $\odot \odot+\odot \odot \odot \odot$ \\
\hline Trief, 2016 & 1.6 & 1.3 & 97 & 2 & 1.3 & 78 & $23.5 \%$ & $-0.31(-0.61,-0.01)$ & --1 & $๑ \odot \odot \odot \odot \odot \odot ~$ \\
\hline Wagner 2016 & 6.3 & 6 & 61 & 7.4 & 6.7 & 46 & $14.4 \%$ & $-0.17(-0.56,0.21)$ & $\rightarrow+$ & $๑ \odot ? \odot \odot ? \div$ \\
\hline Whittemore 2004 & 46.9 & 19 & 25 & 44.1 & 18 & 24 & $6.7 \%$ & $0.15(-0.41,0.71)$ & 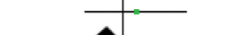 & ????†? ? \\
\hline Subtotal $(95 \% \mathrm{Cl})$ & & & 389 & & & 349 & $100.0 \%$ & $-0.18(-0.32,-0.03)$ & $\bullet$ & \\
\hline \multicolumn{11}{|c|}{$\begin{array}{l}\text { Heterogeneity: } \chi^{2}=3.42, \mathrm{df}=6(P=0.75) ; \quad P=0 \% \\
\text { Test for overall effect: } Z=2.37(P=0.02)\end{array}$} \\
\hline \multicolumn{11}{|c|}{ 2.1.2 Diabetes distress at 6 months } \\
\hline Beverly 2013 & 26.1 & 15.3 & 59 & 28.3 & 22.5 & 62 & $9.9 \%$ & $-0.11(-0.47,0.24)$ & 一 & $\odot \odot+\odot \odot ? \oplus$ \\
\hline Hermanns 2011 & 49.1 & 9.7 & 85 & 48 & 11.2 & 82 & $13.7 \%$ & $0.10(-0.20,0.41)$ & & $๑ \odot \odot ? \odot ? \odot$ \\
\hline Kleinman 2017 (2) & 8.2 & 3.1 & 41 & 9.3 & 5 & 39 & $6.5 \%$ & $-0.26(-0.70,0.18)$ & $\longrightarrow$ & $\odot \odot \odot \odot \odot \odot \odot$ \\
\hline McEwen 2017 & 9.1 & 6.6 & 58 & 11.6 & 8.5 & 54 & $9.1 \%$ & $-0.33(-0.70,0.05)$ & $\longrightarrow$ & ????९? \\
\hline Spencer 2011 (3) & 8.7 & 13.8 & 56 & 12.9 & 20.3 & 74 & $10.4 \%$ & $-0.23(-0.58,0.11)$ & $=-$ & 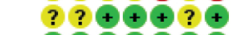 \\
\hline Trief, 2016 (4) & 1.8 & 1.2 & 97 & 2.2 & 1.1 & 78 & $14.0 \%$ & $-0.34(-0.64,-0.04)$ & 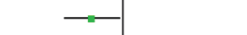 & $\odot \odot \odot \odot \odot \odot \odot ~$ \\
\hline Welch 2015 (5) & 40.4 & 29.6 & 199 & 48.3 & 28.3 & 200 & $32.5 \%$ & $-0.27(-0.47,-0.08)$ & - & ? ? $\odot ? \odot \odot ?$ \\
\hline Whittemore 2004 (6) & 46.9 & 23 & 25 & 42.9 & 19 & 24 & $4.0 \%$ & $0.19(-0.38,0.75)$ & & ? ? ? ?†? \\
\hline Subtotal $(95 \% \mathrm{Cl})$ & & & 620 & & & 613 & $100.0 \%$ & $-0.20(-0.31,-0.08)$ & $\bullet$ & \\
\hline \multicolumn{11}{|c|}{$\begin{array}{l}\text { Heterogeneity: } \chi^{2}=7.88, \mathrm{df}=7(P=0.34) ; P^{2}=11 \% \\
\text { Test for overall effect: } Z=3.44(P=0.0006)\end{array}$} \\
\hline \multicolumn{11}{|c|}{ 2.1.3 Diabetes distress at 12 months } \\
\hline Beverly 2013 & 25 & 16 & 58 & 25.7 & 22.7 & 63 & $12.2 \%$ & $-0.04(-0.39,0.32)$ & $\longrightarrow$ & $\oplus \odot \oplus \ominus \oplus ? \oplus$ \\
\hline D'Eramo 2010 (7) & 38 & 16.6 & 40 & 47 & 16.6 & 37 & $7.5 \%$ & $-0.54(-0.99,-0.08)$ & - & $\odot ? \odot ? \odot \odot \ominus$ \\
\hline McEwen 2017 (8) & 9.9 & 7 & 56 & 10.2 & 6.6 & 50 & $10.7 \%$ & $-0.04(-0.43,0.34)$ & - & ????ด? \\
\hline McMahon 2012 (9) & 19.2 & 18.5 & 51 & 19.5 & 14.8 & 49 & $10.1 \%$ & $-0.02(-0.41,0.37)$ & $\rightarrow$ & $\odot \odot \odot ? \div ?$ \\
\hline Sperl-Hillen 2013 (10) & 23.3 & 13.2 & 489 & 25.7 & 13.3 & 134 & $42.5 \%$ & $-0.18(-0.37,0.01)$ & - & 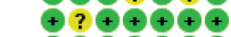 \\
\hline $\begin{array}{l}\text { Trief, } 2016(11) \\
\text { Subtotal }(95 \% \mathrm{Cl})\end{array}$ & 1.7 & 1 & $\begin{array}{r}97 \\
791\end{array}$ & 2.2 & 1 & $\begin{array}{r}78 \\
411\end{array}$ & $\begin{array}{r}17.0 \% \\
100.0 \%\end{array}$ & $\begin{array}{l}-0.50(-0.80,-0.20) \\
-0.21(-0.34,-0.09)\end{array}$ & - & $\odot \odot \odot \odot \odot \odot \odot$ \\
\hline \multicolumn{11}{|c|}{$\begin{array}{l}\text { Heterogeneity: } \chi^{2}=8.11, \mathrm{df}=5(P=0.15) ; P=38 \% \\
\text { Test for overall effect: } Z=3.34(P=0.0008)\end{array}$} \\
\hline \multicolumn{11}{|c|}{ 2.1.4 Diabetes distress at 24 months follow-up } \\
\hline Anderson 2009 & 20.2 & 18.9 & 118 & 22.9 & 19.9 & 124 & $36.9 \%$ & $-0.14(-0.39,0.11)$ & - - & $\oplus \odot ? ?+?$ ? \\
\hline $\begin{array}{l}\text { Gabbay } 2013 \\
\text { Subtotal }(95 \% \text { CI) }\end{array}$ & 23 & 21 & $\begin{array}{l}188 \\
306\end{array}$ & 29 & 27 & $\begin{array}{l}233 \\
357\end{array}$ & $\begin{array}{r}63.1 \% \\
1000 \%\end{array}$ & $\begin{array}{l}-0.24(-0.44,-0.05) \\
-0.21(-0.36-0.05)\end{array}$ & - & 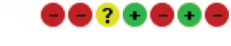 \\
\hline \multirow{2}{*}{\multicolumn{11}{|c|}{$\begin{array}{l}\text { Heterogeneity: } \chi^{2}=0.43, \mathrm{df}=1(P=0.51) ; R=0 \% \\
\text { Test for overall effect: } Z=2.63(P=0.009)\end{array}$}} \\
\hline & & & & & & & & & & \\
\hline & & & & & & & & & -1 & $\frac{1}{2}$ \\
\hline Test for subgroup differ & $\operatorname{ces}: \chi^{2}=0$ & $\mathrm{f}=3$ & $0.98)$ & $=0 \%$ & & & & & & \\
\hline
\end{tabular}

Figure 2 Meta-analysis: intervention vs standard care on diabetes distress at 3, 6, I2, and 24 months follow-up; (I) Means converted from scale with range 0-100 with positive outcomes reflecting a higher number; (2) 24 weeks follow-up; (3) SDs calculated from Cls using Revman 5.3; (4) Measured DDS at 8 months FU (ITT); (5) SDs calculated from SE using Revman 5.3; (6) Significant difference at baseline; PAID 59.9 intervention group versus 42.3 in the control group; (7) Means+SDs from Cochrane review (Chew et al. 2017); (8) Measured with DDS at 9 months follow-up; (9) online care (intervention) versus web training (control); (10) Means+SDs from Cochrane review (chew et al. 2017); (II) Measured with DDS (ITT). Risk of bias legend: (A) Random sequence generation (selection bias); (B) Allocation concealment (selection bias); (C) Blinding of participants and personnel (performance bias); (D) Blinding of outcome assessment (detection bias); (E) Incomplete outcome data (attrition bias); (F) Selective reporting (reporting bias); (G) Other bias.

The quality of evidence was low due to serious risk of bias (summary of findings table not shown).

\section{Health-related quality of life}

HRQOL was a secondary outcome in four studies. ${ }^{45,46,51,53} \mathrm{Bev}-$ erly et al measured HRQOL with diabetes QOL at 12 months follow-up, ${ }^{45}$ and Hermanns et al measured HRQOL with SF-12 mental score at 6 months follow-up. ${ }^{46}$ Gabbay et al did not report results due to nonsignificance, ${ }^{51}$ while D'Eramo Melkus et al reported on selected subscales of QOL only. ${ }^{53}$ Meta-analysis of the two studies reporting results on HRQOL showed an SMD of -0.09 ( $95 \%$ CI $-0.32,0.14), P=0.46$ in favor of the intervention at a mean follow-up of 9 months (forest plot not shown). The quality of evidence was low due to serious risk of bias and imprecision (summary of findings table not shown).

\section{Subgroup analysis on DD}

Subgroup analysis of studies according to intervention intensity showed a significant reduction in DD of both intensive and brief interventions with the most pronounced effect after intensive intervention; intensive intervention SMD -0.20 (95\% CI $-0.29,-0.11), P<0.001$ and brief intervention SMD -0.17 (95\% CI $-0.32,-0.03$ ), $P=0.02$. Subgroup analysis of studies according to individual vs group interventions showed a significant reduction in DD of both individual and group interventions with the most pronounced effect after individual 


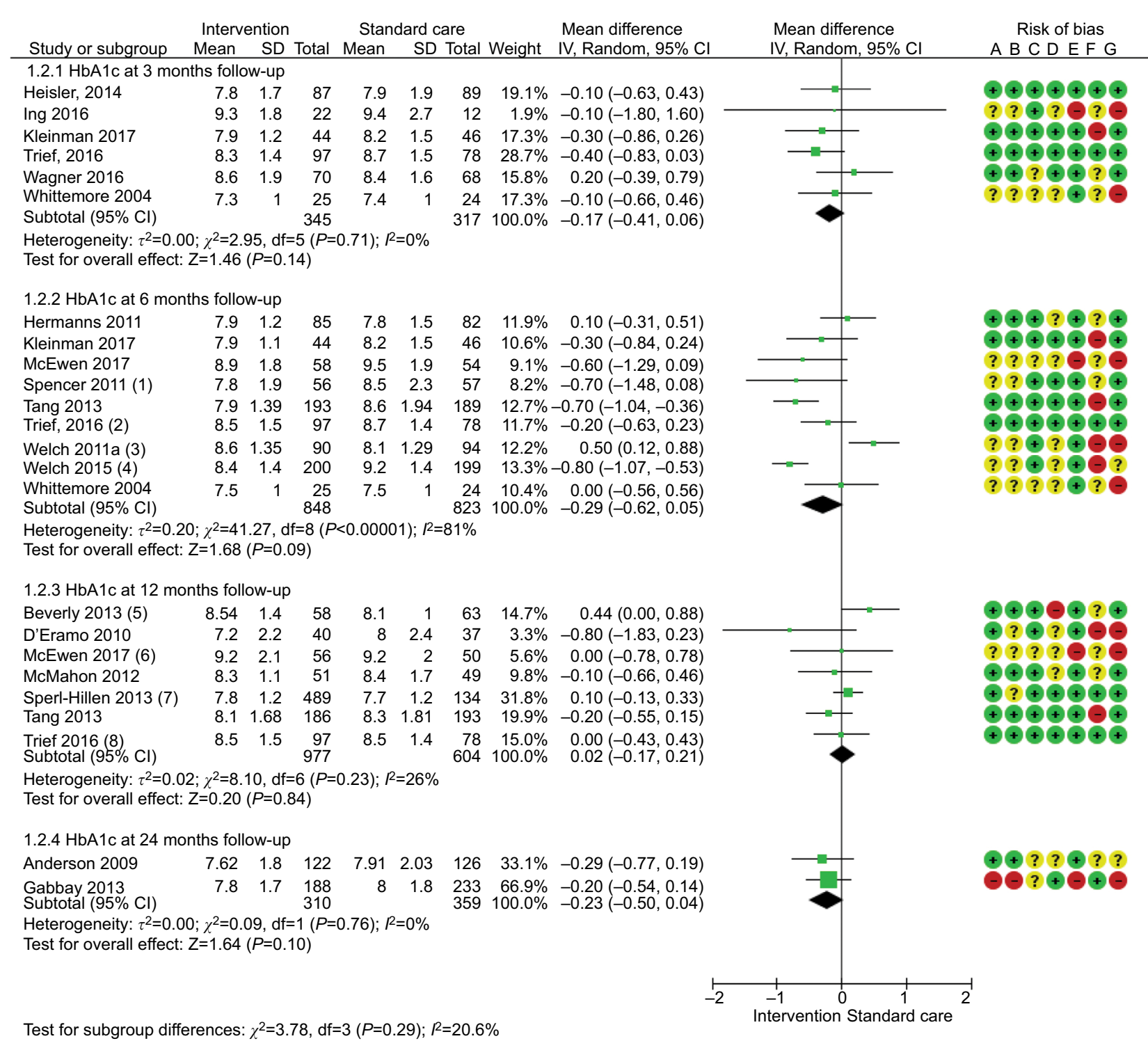

Figure 3 Meta-analysis: intervention vs standard care on HbAlc at 3, 6, I2, and 24 months follow-up; (I) SDs calculated from Cl using Revman 5.3; (2) At 8 months followup (ITT); (3) Mean+SDs calculated from within group differences; (4) SDs Calculated from SE using Revman 5.3; (5) Means+SDs from Cochrance review (Chew et al. 20I7); (6) At 9 months follow-up; (7) Means+SDs from Cochrance review (Chew et al. 20I7); (8) ITT; Risk of bias legend; (A) Random sequence generation (selection bias); (B) Allocation concealment (selection bias); (C) Blinding of participants and personnel (performance bias); (D) Blinding of outcome assessment (detection bias); (E) Incomplete outcome data (attrition bias); (F) Selective reporting (reporting bias); (G) Other bias

intervention; SMD $-0.25(95 \% \mathrm{CI}-0.36,-0.14), P<0.001$ vs SMD $-0.13(-0.24,-0.02), P=0.02$. Subgroup analysis of the three studies incorporating motivational interviewing showed a significant reduction in favor of motivational interviewing; SDM -0.25 (95\% CI $-0.39,-0.10), P=0.001$ (Supplementary material S3; subgroup analyses DD).

\section{Subgroup analysis on HbAlc}

Meta-analysis of studies according to intervention intensity showed a reduction in HbA1c after intensive interventions, but deterioration after brief interventions; $\mathrm{MD}-0.23(95 \%$ $\mathrm{CI}-0.44,-0.01), P=0.04$ and $\mathrm{MD} 0.15$ (95\% CI $-0.11,0.40)$, $P=0.26$, respectively. Meta-analysis of studies according to individual vs group showed a reduction in $\mathrm{HbAlc}$ of individual, but not group intervention; $\mathrm{MD}-0.15$ (95\% CI -0.45 , $0.15), P=0.34$ and MD $0.02(95 \% \mathrm{CI}-0.18,0.21), P=0.86$, respectively. Meta-analysis of studies according to use of motivational interviewing showed a reduction of $-0.08(95 \%$ $\mathrm{CI}-0.43,0.26), P=0.63$ in favor of motivational interviewing (Supplementary material S4).

\section{Sensitivity analysis}

Removing six studies at high risk of attrition bias ${ }^{40,47,49,51-53}$ did not significantly change estimates of intervention effects on DD: SMD $-0.25(95 \% \mathrm{CI}-0.55,0.04) P=0.09$ at 3 months, SMD $-0.19(95 \% \mathrm{CI}-0.31,-0.08) P=0.001$ at 6 months, and 
at 12 months, SMD $-0.19(95 \%$ CI $-0.32,-0.06) P=0.005$. Removing studies with at least one high risk of bias rating reduced effect estimates at 6 months, SMD $-0.15(95 \% \mathrm{CI}$ $-0.33,0.03) P=0.10$ and at 24 months, SMD $-0.14(95 \% \mathrm{CI}$ $-0.39,0.11) P=0.28$, while the effect estimates increased at 3 months, SMD -0.26 (95\% CI $-0.44,0.07) P=0.007$ and at 12 months, SMD $-0.23(95 \% \mathrm{CI}-0.38,-0.09) P=0.002$.

\section{Discussion}

This review provided low to moderate quality evidence for small significant reductions in DD over time and very low to moderate quality evidence for no effect on $\mathrm{HbAlc}$ of psychosocial interventions. We found low quality evidence for a small reduction in depression, and moderate quality evidence for no effect on HRQOL.

The effect on DD was small (SMD $<0.40) ;{ }^{25}$ nevertheless, it may reflect a clinically significant improvement in a highrisk population disproportionately affected by a clustering of risk factors and ensuing high risk of diabetes complications. ${ }^{8,59}$ The most distressed persons are also more likely to have high blood pressure ${ }^{60}$ and high LDL cholesterol, ${ }^{5}$ both factors equally important as $\mathrm{HbAl}$ c for prevention of microand macrovascular complications. ${ }^{61}$ There is evidence for an association between DD and adherence to medication. ${ }^{5,18}$ Reducing DD and thereby increasing treatment adherence might be an intermediate pathway to preventing diabetes complications in this population. In a review also focusing on cognition- and emotion-focused interventions, Chew et al reported nonsignificant reductions in DD in a general population with T2DM. ${ }^{20}$ Our findings indicate that vulnerable people with T2DM might benefit proportionately more from psychosocial interventions targeting DD.

The reduction in DD was not accompanied by a reduction in HbAlc. This opposed to Fisher et al, ${ }^{12}$ who reported a significant association between reduced DD and improved glycemic control during 18 months follow-up in a general T2DM population. Chew et al. reported a borderline significant effect on $\mathrm{HbAlc}$, but as previously mentioned, no effect on DD. ${ }^{20}$

The conflicting findings might be explained by the vulnerability criteria applied in this review including one or more comorbidities ${ }^{62}$ and longer duration of diabetes ${ }^{23}$ which, pathophysiologically ${ }^{63}$ and mentally, might hamper possible effects of interventions on $\mathrm{HbAlc}$ despite reduced levels of DD. From an equity perspective, people with low socioeconomic status, low health literacy, and diabetesrelated sequelae may profit less from interventions, in spite of efforts to tailor interventions to their particular needs. ${ }^{64}$
Hypothetically, not all interventions in included studies were optimally customized to this specific population. Furthermore, vulnerability may affect adherence to interventions in clinical trials. ${ }^{65}$ An implication of our findings could be stratified interventions for patients with low health literacy, social problems, and language and logistic barriers. This could accommodate access, attendance, and integration of interventions and potentially reduce attrition in this group of patients. Stratified interventions would likely require training of health care professionals in culturally and literacy sensitive aspects of person-centered diabetes care.

The lacking effect on HbA1c lends support to previous research suggesting a noncausal link between DD and HbA1c. ${ }^{13}$ However, provision of preintervention to all participants prior to randomization in three studies ${ }^{40,49,54}$ and enhanced standard care to control groups in eleven studies $^{40,42,44-47,49,52-54,58}$ might also have played a role. Previous trials have moreover suggested that behavioral interventions may be more effective in people with a poorer baseline psychological state ${ }^{66}$ while other studies link their effectiveness to having intervened on people with $\mathrm{HbAl} 1 \mathrm{c} \geq 9.0 \%$ (75 mmol/ mol) ${ }^{67}$ Indeed, the baseline levels of both DD (mean 39 \pm 10.8 ) and $\mathrm{HbA} 1 \mathrm{c} 8.7 \%$ (mean 72 \pm 7.7 ) were clinically important in the studies included ${ }^{68}$ Preinterventions and enhanced standard care may, however, have weakened the level to which DD and HbAlc could be reduced. This explanation is supported by the weaker effect of interventions at 3 months compared with 6 months contradictory to the well-established Hawthorne effect. ${ }^{69}$

There was low quality evidence from four studies for a small but significant reduction in depression. This lends support to the suggested link between depression and $\mathrm{DD}^{9}$ and may have clinical potential if there is an association between reduced depression and improved diabetes self-management, as previously reported..$^{18}$ Our results may, however, reflect the instruments used to measure depression in included studies. According to Fisher et al, depression should be assessed using a gold standard structured clinical interview. ${ }^{11}$ Preferably, this approach should be used uniformly to distinguish depression from DD and direct care effectively. ${ }^{11}$ Despite the heterogeneous instruments used, studies have reported a disproportionate burden of depression in people with T2DM. ${ }^{70}$ Similar to our findings, other studies also failed to identify improvements in glycemic control despite reduction in depression. ${ }^{13,71}$

Exploratory subgroup analysis indicated a deteriorating effect of brief interventions on HbA1c. This could indicate that vulnerable people with T2DM benefit less from brief 
interventions, perhaps because they lack individualized peer support. ${ }^{72}$ This points toward a need for continuity and a designated health care professional as proposed in other studies. $^{73,74}$ The explorative subgroup analyses of effects on DD of individual vs group and intensive vs brief interventions endorse this interpretation.

Subgroup analysis of interventions incorporating motivational interviewing indicated a potential association with reduced DD. Again, this effect did not "spill over" on HbA1c, although it should be noted that only one of the studies included in the analysis identified an increase in HbA1c. ${ }^{57}$ This study tested a brief intervention and was at high risk of bias, primarily due to attrition $(35 \%) .{ }^{57}$

Our results lend support to the relevance of further research on person-centered care such as motivational interviewing for reducing DD, and increasing glycemic control in vulnerable people with T2DM. ${ }^{21}$ Diverse theoretical foundations determined the content of interventions. Notwithstanding the value of theoretically founded interventions, there is some concern about a potential gap between theory and the implementation of person-centered care in clinical practice. ${ }^{75}$ If interventions do not sufficiently reflect the theoretical foundation, effect may be weakened. Our review nevertheless adds further to the potential promise of person-centered care, eg, motivational interviewing including person-centered support from a devoted person for vulnerable people with T2D. Such approaches should consider the patients' everyday life including their social network and life values.

\section{Strengths and limitations}

This review adhered to the Cochrane Collaboration's methodology for systematic reviews to rigorously examine the evidence for an effect of psychosocial interventions vs standard care on DD and, secondly, on HbAlc, depression, and HRQOL in vulnerable people with T2DM. Nonetheless, several factors might have influenced effect estimates.

We applied the SMD on outcomes where studies used different instruments for measuring DD, depression, and HRQOL. The application of the SMD has, however, been reported to be inaccurate and even erroneous ${ }^{76}$ due to data extraction errors, mistakes in calculations, or confusion regarding the direction of the included scales for specific outcomes. To avoid these pitfalls, our data extraction process was performed twice by each reviewer to ensure accuracy. Moreover, we used Review Manager to perform calculations and chose to include only studies using validated instruments (PAID and DDS).

Secondly, sensitivity analysis revealed that removing studies with high risk of bias reduced effect estimates on DD at
6 and 24 months follow-up, while they increased at 3 and 12 months. The results remained statically significant at 3 and 12 months follow-up only. This differs from the findings of Savovic et al, who concluded that low quality studies are more likely to report large effect sizes. ${ }^{77}$ Removing studies with high attrition marginally attenuated effect estimates on DD. This might indicate a minor overestimation of effect sizes due to high attrition. However, the effect on DD at 6 and 12 months remained statistically significant.

Thirdly, poor reporting of results and missing information resulted in an assessment of most studies as being at "unclear" risk of bias. Likewise, in studies with insufficient reporting, some authors stated that lack of reported results was due to nonsignificant differences between groups at follow-up. ${ }^{56}$ Consequently, studies showing no increase or decrease in outcomes were not included in meta-analyses, potentially leading to overestimation of effects. Inclusion of a wait-list design in three studies might have induced anticipation bias and reduced between-group differences at follow-up. Moreover, the use of available case analysis may have augmented the effect on all outcomes.

Baseline DD values differed significantly between the intervention and the control groups in four studies. ${ }^{47,48,55,44}$ Due to nonreporting of change scores in eleven studies $^{41,45,47-51,53-56}$ and the use of different instruments for measuring DD, we considered that post hoc exploratory analyses using available change scores would be misleading. ${ }^{25}$ Moreover, imbalance between groups at baseline should be eliminated in meta-analysis. ${ }^{36}$

If the effects of emotion- vs cognition-based interventions could be distinguished, it might have strengthened the review. However, some of the most cited theoretical models underlying the interventions, eg, Bandura's model on self-efficacy, ${ }^{30,31}$ involve both emotion- and cognition-based constructs. Therefore, we were unable to distinguish effects of interventions according to underlying theory. The generalizability of our findings might be limited by the inclusion of only two studies originating from other countries than United States.

\section{Conclusion}

We found low to moderate quality evidence for a significant, but small reduction in DD and very low to moderate quality evidence for no effect on HbA1c at 3, 6, 12, and 24 months follow-up of psychosocial interventions. The reduction in depression was significant, but small, while there was no effect on HRQOL. Exploratory subgroup analyses showed significant incremental reductions in DD and HbA1c of intensive ( $>4$ sessions) vs brief interventions. On HbAlc, there was a nonsignificant trend toward deteriorating $\mathrm{HbA} 1 \mathrm{c}$ 
after brief intervention. Individual and group interventions significantly reduced DD, but not $\mathrm{HbA1}$. On both outcomes the largest reductions were found after individual interventions. Subgroup analysis of interventions using motivational interviewing was associated with larger effects on DD, but not on $\mathrm{HbAlc}$.

\section{Acknowledgments}

This review was funded by the University Hospital of Copenhagen, Rigshospitalet, grant number E-22260-04, Denmark, TRYG Foundation, Denmark, Grant number 103925, The Novo Nordisk Foundation, Denmark, Grant Number 6265, and the Lundbeck Foundation, Denmark. The funding sources had no role in any stage of the research process.

\section{Author contributions}

Literature searches were performed by ASM. The initial screening of title and abstract, including full-text screening, was performed by ASM and TT. Data from studies eligible for inclusion were extracted and bias assessed by ASM and GK with disagreement solved by IE or TT. Meta-analyses and GRADE assessments were conducted by ASM and TT. All authors contributed to data analysis, drafting and revising the article, gave final approval of the version to be published, and agree to be accountable for all aspects of the work.

\section{Disclosure}

The authors report no conflicts of interest in this work.

\section{References}

1. Polonsky WH, Anderson BJ, Lohrer PA, et al. Assessment of diabetesrelated distress. Diabetes Care. 1995;18(6):754-760.

2. Lipscombe C, Burns RJ, Schmitz N. Exploring trajectories of diabetes distress in adults with type 2 diabetes; a latent class growth modeling approach. J Affect Disord. 2015;188:160-166.

3. Fisher L, Skaff MM, Mullan JT, Arean P, Glasgow R, Masharani U. A longitudinal study of affective and anxiety disorders, depressive affect and diabetes distress in adults with Type 2 diabetes. Diabet Med. 2008;25(9):1096-1101.

4. Stoop CH, Nefs G, Pop VJ, et al. Diabetes-specific emotional distress in people with Type 2 diabetes: a comparison between primary and secondary care. Diabet Med. 2014;31(10):1252-1259.

5. Pandit AU, Bailey SC, Curtis LM, et al. Disease-related distress, selfcare and clinical outcomes among low-income patients with diabetes. J Epidemiol Community Health. 2014;68(6):557-564.

6. Hessler D, Fisher L, Glasgow RE, et al. Reductions in regimen distress are associated with improved management and glycemic control over time. Diabetes Care. 2014;37(3):617-624.

7. Zulman DM, Rosland AM, Choi H, Langa KM, Heisler M. The influence of diabetes psychosocial attributes and self-management practices on change in diabetes status. Patient Educ Couns. 2012;87(1):74-80.

8. Kasteleyn MJ, de Vries L, van Puffelen AL, et al. Diabetes-related distress over the course of illness: results from the Diacourse study. Diabet Med. 2015;32(12):1617-1624.
9. Burns RJ, Deschênes SS, Schmitz N. Cyclical relationship between depressive symptoms and diabetes distress in people with Type 2 diabetes mellitus: results from the Montreal Evaluation of Diabetes Treatment Cohort Study. Diabet Med. 2015;32(10):1272-1278.

10. Park M, Katon WJ, Wolf FM. Depression and risk of mortality in individuals with diabetes: a meta-analysis and systematic review. Gen Hosp Psychiatry. 2013;35(3):217-225.

11. Fisher L, Gonzalez JS, Polonsky WH. The confusing tale of depression and distress in patients with diabetes: a call for greater clarity and precision. Diabet Med. 2014;31(7):764-772.

12. Fisher L, Glasgow RE, Strycker LA. The relationship between diabetes distress and clinical depression with glycemic control among patients with type 2 diabetes. Diabetes Care. 2010;33(5):1034-1036.

13. Fisher L, Mullan JT, Arean P, Glasgow RE, Hessler D, Masharani U. Diabetes distress but not clinical depression or depressive symptoms is associated with glycemic control in both cross-sectional and longitudinal analyses. Diabetes Care. 2010;33(1):23-28.

14. Shivayogi P. Vulnerable population and methods for their safeguard. Perspect Clin Res. 2013;4(1):53-57.

15. Walker RJ, Smalls BL, Egede LE. Social determinants of health in adults with type 2 diabetes--contribution of mutable and immutable factors. Diabetes Res Clin Pract. 2015;110(2):193-201.

16. Cutrona CE, Abraham WT, Russell DW, et al. Financial strain, inflammatory factors, and haemoglobin A1c levels in African American women. Br J Health Psychol. 2015;20(3):662-679.

17. Wardian JL, Tate J, Folaron I, Graybill S, True M, Sauerwein T. Who's distressed? A comparison of diabetes-related distress by type of diabetes and medication. Patient Educ Couns. 2018;101(8):1490-1495.

18. Aikens JE. Prospective associations between emotional distress and poor outcomes in type 2 diabetes. Diabetes Care. 2012;35(12):2472-2478.

19. Dennick K, Sturt J, Speight J. What is diabetes distress and how can we measure it? A narrative review and conceptual model. J Diabetes Complications. 2017;31(5):898-911.

20. Chew BH, Vos RC, Metzendorf MI, Scholten RJ, Rutten GE. Psychological interventions for diabetes-related distress in adults with type 2 diabetes mellitus. Cochrane Database Syst Rev. 2017;9:CD011469.

21. Sturt J, Dennick K, Hessler D, Hunter BM, Oliver J, Fisher L. Effective interventions for reducing diabetes distress: systematic review and meta-analysis. Int Diab Nurs. 2015;12(2):40-55.

22. Fisher L, Hessler DM, Polonsky WH, Mullan J. When is diabetes distress clinically meaningful?: establishing cut points for the Diabetes Distress Scale. Diabetes Care. 2012;35(2):259-264.

23. Lamers F, Jonkers CC, Bosma H, Knottnerus JA, van Eijk JT. Treating depression in diabetes patients: does a nurse-administered minimal psychological intervention affect diabetes-specific quality of life and glycaemic control? A randomized controlled trial. JAdv Nurs. 2011;67(4):788-799.

24. Shamseer L, Moher D, Clarke M, et al. Preferred reporting items for systematic review and meta-analysis protocols (PRISMA-P) 2015: elaboration and explanation. BMJ. 2015;349:g7647.

25. Cochrane Handbook for Systematic Reviews of Interventions: Cochrane Book Series. Vol 5.1.0: London, UK: The Cochrane Collaboration; 2011.

26. Dagogo-Jack S. Ethnic disparities in type 2 diabetes: pathophysiology and implications for prevention and management. J Natl Med Assoc. 2003;95(9):774-789.

27. O’Neill J, Tabish H, Welch V, et al. Applying an equity lens to interventions: using PROGRESS ensures consideration of socially stratifying factors to illuminate inequities in health. J Clin Epidemiol. 2014;67(1):56-64.

28. Chiang JL, Kirkman MS, Laffel LM, Peters AL, Type 1 Diabetes Sourcebook Authors. Type 1 diabetes through the life span: a position statement of the American Diabetes Association. Diabetes Care. 2014;37(7):2034-2054.

29. Chew BH, Shariff-Ghazali S, Fernandez A. Psychological aspects of diabetes care: effecting behavioral change in patients. World J Diabetes. 2014;5(6):796-808.

30. Bandura A, Adams NE, Beyer J. Cognitive processes mediating behavioral change. J Pers Soc Psychol. 1977;35(3):125-139. 
31. Bandura A, Cioffi D, Taylor CB, Brouillard ME. Perceived self-efficacy in coping with cognitive stressors and opioid activation. J Pers Soc Psychol. 1988;55(3):479-488.

32. Polonsky WH, Fisher L, Earles J, et al. Assessing psychosocial distress in diabetes: development of the diabetes distress scale. Diabetes Care. 2005;28(3):626-631.

33. Snoek FJ, Bremmer MA, Hermanns N. Constructs of depression and distress in diabetes: time for an appraisal. Lancet Diabetes Endocrinol. 2015;3(6):450-460.

34. Kroenke K, Spitzer RL, Williams JB. The PHQ-9: validity of a brief depression severity measure. J Gen Intern Med. 2001;16(9):606-613.

35. Covidence Systematic Review Software. Covidence systematic review software, Veritas Health Innovation, Melbourne, Australia. Available from: www.covidence.org. Accessed November 16, 2018.

36. Higgins JP, Altman DG, Gøtzsche PC, et al. The Cochrane Collaboration's tool for assessing risk of bias in randomised trials. $B M J$. 2011;343:d5928.

37. Sterne JA, Sutton AJ, Ioannidis JP, et al. Recommendations for examining and interpreting funnel plot asymmetry in meta-analyses of randomised controlled trials. BMJ. 2011;343:d4002.

38. Ritzwoller DP, Sukhanova AS, Glasgow RE, et al. Intervention costs and cost-effectiveness for a multiple-risk-factor diabetes self-management trial for Latinas: economic analysis of ¡Viva Bien! Transl Behav Med. 2011;1(3):427-435.

39. Guyatt GH, Oxman AD, Vist GE, et al. GRADE: an emerging consensus on rating quality of evidence and strength of recommendations. $B M J$. 2008;336(7650):924-926.

40. Ing CT, Zhang G, Dillard A, et al. Social support groups in the maintenance of glycemic control after community-based intervention. $J$ Diabetes Res. 2016;2016:7913258-8.

41. Sperl-Hillen J, Beaton S, Fernandes O, et al. Are benefits from diabetes self-management education sustained? Am J Manag Care. 2013;19(2):104-112.

42. Heisler M, Choi H, Palmisano G, et al. Comparison of community health worker-led diabetes medication decision-making support for low-income Latino and African American adults with diabetes using e-health tools versus print materials: a randomized, controlled trial. Ann Intern Med. 2014;161(10 Suppl):S13-S22.

43. Spencer MS, Rosland AM, Kieffer EC, et al. Effectiveness of a community health worker intervention among African American and Latino adults with type 2 diabetes: a randomized controlled trial. Am J Public Health. 2011;101(12):2253-2260.

44. Mcmahon GT, Fonda SJ, Gomes HE, Alexis G, Conlin PR. A randomized comparison of online- and telephone-based care management with internet training alone in adult patients with poorly controlled type 2 diabetes. Diabetes Technol Ther. 2012;14(11):1060-1067.

45. Beverly EA, Fitzgerald SM, Brooks KM, et al. Impact of reinforcement of diabetes self-care on poorly controlled diabetes: a randomized controlled trial. Diabetes Educ. 2013;39(4):504-514.

46. Hermanns N, Kulzer B, Maier B, Mahr M, Haak T. The effect of an education programme (MEDIAS 2 ICT) involving intensive insulin treatment for people with type 2 diabetes. Patient Educ Couns. 2012;86(2):226-232.

47. Kleinman NJ, Shah A, Shah S, Phatak S, Viswanathan V. Improved medication adherence and frequency of blood glucose self-testing using an $\mathrm{m}$-Health Platform Versus usual care in a multisite randomized clinical trial among people with type 2 diabetes in India. Telemed $J E$ Health. 2017;23(9):733-740.

48. Welch G, Zagarins SE, Santiago-Kelly P, et al. An internet-based diabetes management platform improves team care and outcomes in an urban Latino population. Diabetes Care. 2015;38(4):561-567.

49. Wagner JA, Bermudez-Millan A, Damio G, et al. A randomized, controlled trial of a stress management intervention for Latinos with type 2 diabetes delivered by community health workers: outcomes for psychological wellbeing, glycemic control, and cortisol. Diabetes Res Clin Pract. 2016;120:162-170.
50. Mcewen MM, Pasvogel A, Murdaugh C, Hepworth J. Effects of a familybased diabetes intervention on behavioral and biological outcomes for Mexican American adults. Diabetes Educ. 2017;43(3):272-285.

51. Gabbay RA, Añel-Tiangco RM, Dellasega C, Mauger DT, Adelman A, van Horn DH. Diabetes nurse case management and motivational interviewing for change (DYNAMIC): results of a 2-year randomized controlled pragmatic trial. J Diabetes. 2013;5(3):349-357.

52. Anderson RM, Funnell MM, Aikens JE, et al. Evaluating the efficacy of an empowerment-based self-management consultant intervention: results of a two-year randomized controlled trial. Ther Patient Educ. 2009;1(1):3-11.

53. D'Eramo Melkus G, Chyun D, Vorderstrasse A, Newlin K, Jefferson V, Langerman $\mathrm{S}$. The effect of a diabetes education, coping skills training, and care intervention on physiological and psychosocial outcomes in black women with type 2 diabetes. Biol Res Nurs. 2010;12(1):7-19.

54. Trief PM, Fisher L, Sandberg J, et al. Health and psychosocial outcomes of a telephonic couples behavior change intervention in patients with poorly controlled type 2 diabetes: a randomized clinical trial. Diabetes Care. 2016;39(12):2165-2173.

55. Whittemore R, Melkus GD, Sullivan A, Grey M. A nurse-coaching intervention for women with type 2 diabetes. Diabetes Educ. 2004;30(5):795-804

56. Tang PC, Overhage JM, Chan AS, et al. Online disease management of diabetes: engaging and motivating patients online with enhanced resources-diabetes (EMPOWER-D), a randomized controlled trial. $J$ Am Med Inform Assoc. 2013;20(3):526-534.

57. Welch G, Zagarins SE, Feinberg RG, Garb JL. Motivational interviewing delivered by diabetes educators: does it improve blood glucose control among poorly controlled type 2 diabetes patients? Diabetes Res Clin Pract. 2011;91(1):54-60.

58. Welch G, Allen NA, Zagarins SE, Stamp KD, Bursell SE, Kedziora RJ. Comprehensive diabetes management program for poorly controlled Hispanic type 2 patients at a community health center. Diabetes Educ. 2011;37(5):680-688.

59. Larrañaga I, Arteagoitia JM, Rodriguez JL, et al. Socio-economic inequalities in the prevalence of Type 2 diabetes, cardiovascular risk factors and chronic diabetic complications in the Basque Country, Spain. Diabet Med. 2005;22(8):1047-1053.

60. Chew BH, Sherina MS, Hassan NH. Association of diabetes-related distress, depression, medication adherence, and health-related quality of life with glycated hemoglobin, blood pressure, and lipids in adult patients with type 2 diabetes: a cross-sectional study. Ther Clin Risk Manag. 2015;11:669-681.

61. Oellgaard J, Gæde P, Rossing P, et al. Reduced risk of heart failure with intensified multifactorial intervention in individuals with type 2 diabetes and microalbuminuria: 21 years of follow-up in the randomised Steno-2 study. Diabetologia. 2018;61(8):1724-1733.

62. Chiu CJ, Yh H, Wray LA. Dissemination of evidence-base minimal psychological intervention for diabetes management in Taiwan adults with type 2 diabetes. Int J Clin Exp Med. 2016;9(7):14489-14498.

63. Intensive blood-glucose control with sulphonylureas or insulin compared with conventional treatment and risk of complications in patients with type 2 diabetes (UKPDS 33). UK Prospective Diabetes Study (UKPDS) Group. Lancet. 1998;352(9131):837-853.

64. Schillinger D, Grumbach K, Piette J, et al. Association of health literacy with diabetes outcomes. JAMA. 2002;288(4):475-482.

65. Maindal HT, Skriver MV, Kirkevold M, Lauritzen T, Sandbaek A. Comorbidity and lack of education countered participation in a diabetes prevention self-management program. $J$ Nurs Healthc Chronic Illn. 2011;3(3):293-301

66. Robertson SM, Amspoker AB, Cully JA, Ross EL, Naik AD. Affective symptoms and change in diabetes self-efficacy and glycaemic control. Diabet Med. 2013;30(5):e189-e196.

67. Health Quality Ontario. Behavioural Interventions for type 2 diabetes: an evidence-based analysis. Ont Health Technol Assess Ser. 2009;9(21):1-45. 
68. Holman RR, Paul SK, Bethel MA, Matthews DR, Neil HAW. 10-year follow-up of intensive glucose control in type 2 diabetes. NEngl J Med Overseas Ed. 2008;359(15):1577-1589.

69. Mccarney R, Warner J, Iliffe S, van Haselen R, Griffin M, Fisher P. The Hawthorne Effect: a randomised, controlled trial. BMC Med Res Methodol. 2007;7(1):30.

70. Naranjo DM, Fisher L, Areán PA, Hessler D, Mullan J. Patients with type 2 diabetes at risk for major depressive disorder over time. Ann Fam Med. 2011;9(2):115-120.

71. Williams JW, Katon W, Lin EH, et al. The effectiveness of depression care management on diabetes-related outcomes in older patients. Ann Intern Med. 2004;140(12):1015-1024.

72. Sokol R, Fisher E. Peer support for the hardly reached: a systematic review. Am J Public Health. 2016;106(7):e1-e8.

73. Torenholt R, Varming A, Engelund G, et al. Simplicity, flexibility, and respect: preferences related to patient education in hardly reached people with type 2 diabetes. Patient Prefer Adherence. 2015;9:1581-1586.
74. Mathiesen AS, Thomsen T, Jensen T, Schiøtz C, Langberg H, Egerod I. The influence of diabetes distress on digital interventions for diabetes management in vulnerable people with type 2 diabetes: a qualitative study of patient perspectives. J Clin Transl Endocrinol. 2017;9:41-47.

75. Zoffmann V, Hörnsten Å, Storbækken S, et al. Translating personcentered care into practice: a comparative analysis of motivational interviewing, illness-integration support, and guided self-determination. Patient Educ Couns. 2016;99(3):400-407.

76. Gøtzsche PC, Hróbjartsson A, Marić K, Tendal B. Data extraction errors in meta-analyses that use standardized mean differences. JAMA. 2007;298(4):430-437.

77. Savovic J, Turner RM, Mawdsley D. Association between risk-of-bias assessments and results of randomized trials in Cochrane reviews: the ROBES Meta-Epidemiologic Study. Am J Epidemiol. 2018;187(5):1113-1122.

\section{Publish your work in this journal}

Diabetes, Metabolic Syndrome and Obesity: Targets and Therapy is an international, peer-reviewed open-access journal committed to the rapid publication of the latest laboratory and clinical findings in the fields of diabetes, metabolic syndrome and obesity research. Original research, review, case reports, hypothesis formation, expert opinion and commentaries are all considered for publication. The manuscript management system is completely online and includes a very quick and fair peer-review system, which is all easy to use. Visit http://www.dovepress.com/testimonials.php to read real quotes from published authors.

Submit your manuscript here: https://www.dovepress.com/diabetes-metabolic-syndrome-and-obesity-targets-and-therapy-journal 